\title{
Labor documental para programas de entretenimiento en las televisiones
}

\section{Jorge Caldera-Serrano}

Profesor de la Facultad de Biblioteconomía y Documentación de la Universidad de Extremadura (España)

E-mail: jcalser@alcazaba.unex.es

\section{Resumo}

Se presentan las diferentes áreas con las que han de contar las bases de datos para el control de la documentación audiovisual en el marco de la gestión, conservación y difusión de los programas de entretenimiento de las televisiones. Se muestran las áreas control, producción, emisión, descripción física, descriptores temáticos, geográficos, cronológicos, título, responsabilidad y localización. Además se presentan una serie de peculiaridades de difusión de dicha información. Igualmente se lleva a cabo una tipología de los programas que se realizan y producen en las empresas televisivas.

\section{Palavras-chave}

Documentação audiovisual. Gestão informacional. Televisão. Programas de entretenimento.

\section{Documentary work for television entertainment programs}

\begin{abstract}
Presents different areas with which databases are going to rely on for the control of audiovisual documentation within the framework of management, conservation and diffusion of television entertainment programs. The areas under concern are control, production, emission, physical description, thematic, geographic and chronological headings, title, responsibility and location. Besides this, a series of features of the information diffusion are presented, along with a typology of the programs produced and carried out by the television enterprises.
\end{abstract}

\section{Keywords}

Audiovisual documentation. Information management. Television. Entertainment programs.

\section{INTRODUCCIÓN}

La televisión, cuestionada y admirada, discutida y ensalzada, criticada y alabada. El Cuarto Poder, término con el que se conoce a los medios de comunicación, ha conseguido plasmar en la televisión muchas de sus aspiraciones comunicativas, siendo el medio más universal para la recepción de la información. Su facilidad de consumo hace que millones de personas no sólo adquieran información por medio de esta vía sino que también sea la principal fórmula de divertimento y ocio en nuestra sociedad. La televisión nunca ha sido un fiel reflejo de la sociedad, sino de aquello que los grandes medios de comunicación quisieran que fuera la sociedad. Se han conseguido internacionalizar necesidades y contenidos, conformando lo que MacLujan denominara la aldea global, en la que una gran multitud se convierte en receptores de información idéntica y por lo tanto universal.

La televisión, con sus ventajas e inconvenientes, con sus pros y sus contras, con sus puntos fuertes y débiles, con su manipulación e ideologización, es el método por el que conseguimos entender y relacionarnos con un entorno internacional cada vez más complejo y difícil de asimilar.

Todas las cadenas televisivas, para una correcta gestión de sus contenidos audiovisuales, cuentan con departamentos de información y documentación (más o menos importantes) con el fin no sólo de conservar sino de poner a disposición una gran cantidad de información a los trabajadores de las empresas audiovisuales. De todas maneras, el servicio de documentación trabaja para la conservación y difusión de un activo empresarial tan importante como pueden ser los recursos humanos y los recursos económicos: los recursos intelectuales. Estos recursos, patrimonio audiovisual de la propia organización y del país, cuentan también con la potencialidad de ser vendidos a otras compañías como al público en general.

Se va a intentar mostrar el desarrollo de la labor documental en las empresas audiovisual analizando programas de entretenimiento, por lo que hablamos de 
documentación audiovisual en televisión, documentación audiovisual que, en este caso, va a coincidir prácticamente con productos preparados para su emisión.

\section{PROGRAMACIÓN Y ENTRETENIMIENTO EN TELEVISION}

Esta distinción entre programas de entretenimiento y programas informativos es una realidad en la práctica totalidad de las cadenas debido a una clara situación, la cual evidencia que las necesidades de los usuarios de uno y otros servicios son diferentes, además de contar con unas características documentales absolutamente dispares.

Existen ya diferentes publicaciones que analizan la gestión de la documentación audiovisual (o de imagen en movimiento) atendiendo a su naturaleza informativa, entre los cuales cabría destacar los noticiarios y los info show (talk show, reality show y magazine).

Para poder engarzar, de manera sublime, los diferentes productos audiovisuales en una parrilla programática es necesario llevar a cabo el delicado ejercicio de la programación. Blum y Lindeheim (1997, p. 17) proponen que la programación es un concepto relacionado con la presentación visual del producto, siendo variada las formas y formatos en los que puede presentarse como series de humor, series dramáticas, programas de acción películas, miniseries, programas especiales, deportes, programas infantiles, etc. Igualmente señalan que el concepto de programación es diferente para el telespectador y el profesional, contando para este último con la doble vertiente de encontrar y desarrollar nuevos espectáculos y emitir programas que compitan contra otros programas ofertados.

Por lo tanto, cada uno de los programas de una cadena es una pequeña parte de un total mucho mayor que es la programación. Cada uno de los productos de entretenimiento de la cadena son un microdiscurso que conforma la parrilla de la cadena, al igual que en el conjunto de un programa existen pequeñas partes que la conforman. Los informativos, por ejemplo, cuentan también con un discurso dentro de cada una de las noticias, en el marco de cada una de las secciones y, en último lugar, en el conjunto del informativo, siendo el total del informativo el que se agrupa en la parrilla de la programación de la empresa. Toda la programación debe ser coherente y unitaria atendiendo a criterios empresariales, los cuales están asociados a juicios económicos, humanos e ideológicos (Contreras, 2001, p. 13).

Es evidente e incuestionable la rápida evolución de las emisiones de televisión, evolución que es imparable al tener que ir en paralelo a las peculiaridades de los telespectadores cuyos gustos son eminentemente cambiantes, debiendo esforzarse en no caer en la reiteración de productos ni en la obsolescencia de los mismos. Diversión y diversidad deben ser las piezas claves como criterios para la evolución de la programación televisiva.

La programación debe adaptarse también a los horarios y a los telespectadores que consumen televisión en esa franja horaria. En la programación actual, de una televisión emitiendo las veinticuatro horas al día, pueden observarse una serie de fase en la evolución de la programación. Además, la programación conjunta de un día completo no termina ni comienza con el fin del día sino que se corresponden con el final del hecho programático que puede ser a las seis de la mañana, aproximadamente, en el momento en el que acaba la programación nocturna y comienza la diurna.

Mariano Cebrian Herreros (1998, p. 386), habla de diferentes tipos de programas atendiendo a varios grados de especialización:

- Dirigidos a expertos.

Reservado para temas altamente especializados, siendo el telespectador el especialista en una materia determinada. Un posible ejemplo de ello podrían ser los canales de medicina, arquitectura, etc. Sin lugar a dudas, el aumento de los canales temáticos como fórmula de fragmentación de la audiencia es un concepto reciente en la forma de entender la programación en nuestro país, lo cual no delimita su potencial futuro (junto con las cadenas locales).

- Dirigidos a interesados en una materia determinada.

Esta forma de entender la programación cuenta con una peculiaridad que la define y diferencia respecto al anteriormente indicado, y es que aunque su naturaleza y objetivos están enmarcadas en la televisión temática, va dirigida a un tipo de audiencia absolutamente general y heterogénea, siendo tan solo necesario que cuenten con un pequeño bagaje informacional del asunto para su consumo, lo que se adquiere fácilmente haciendo entendible el producto para la mayor parte de los telespectadores. 
- Dirigidos a una audiencia general con programación abierta.

En el marco de este tipo de programas contamos con una tipología de programas de entretenimiento e informativos que vamos a reseñar brevemente.

\section{Informativos}

Los programas informativos suelen estar separados orgánicamente a la hora de la realización de la gestión documental, derivado de diferentes cuestiones tales como el tipo documentación y, muy especialmente, la potencialidad de recuperación de recursos y totales.

Una posible tipología de géneros en el marco de los programas informativos podría ser la siguiente:

\section{NOTICIARIO}

\section{Telediario}

Avance informativo

Resumen

Especiales informativos

\author{
INFO SHOW \\ Talk show \\ Reality Show \\ Magazine
}

La programación informativa debe ser y es una de las piezas fundamentales de la programación de la cadena, vertebrando y estructurando el resto de programas. Los informativos son la piedra angular de la cadena y la que define la línea programática e ideológica, destinándose grandes esfuerzos desde el punto de vista de los recursos económicos y de los recursos humanos.

\section{Deportivos}

Los programas deportivos han tomado especial relevancia en la última década, lo que ha hecho posible que se incremente no sólo el número de programas destinados a los diferentes eventos deportivos como al aumento de minutos, de manera inusitada y desesperante, en los informativos en formato noticiario. Dicho aumento de tiempo destinado a la temática deportiva ha venido relacionado con el aumento de telespectadores que demanda dichos productos. Los canales temáticos deportivos están teniendo una gran relevancia en la fracturación y especialización de la audiencia. Las transmisiones en directo de eventos deportivos es la principal apuesta en la programación de muchas de las cadenas generalistas y familiares, ya que la adquisición de los derechos de difusión suelen ser excesivamente cuantiosas.

\section{Economía}

Con escasa relevancia social han sido relegados a horarios muy determinados derivado a una audiencia fija pero escasa. Parece que el medio audiovisual, en la tendencia actual a la espectacularidad, no tiene cabida una información excesivamente sesuda que requiere una atención y preparación previa a la que no parece estar dispuesta el conjunto de la audiencia.

\section{Programas "rosas” y “del corazón”}

Si alarmante es el incremento en minutos destinados a la información deportiva, vergonzante y bochornoso para los programadores debiera ser la explosión de programas de temática banal aunque de fácil consumo. Los programas rosas y del corazón han tenido un gran éxito de audiencia en los últimos años, desconociendo aún cuándo y dónde pueden "tocar techo" dichos productos, que suelen ser presentado por personajes populares con mucho gancho y seguidores, que trata sobre cuestiones personales de personajes famosos, populares y de acólitos de los anteriores.

\section{Programas de temática retrospectiva}

Este bloque se refiere a programas que, eventualmente, suelen emitirse en alguna de las cadenas españolas como pueden ser programas sobre acontecimientos históricos, aquellos que versan sobre una persona determinada aportando una biografía documentada, programas realizados a partir del archivo, etc.

\section{Programas políticos}

Aunque el aumento del interés por la prensa rosa y del corazón es real y palpable por medio de las audiencias, no es menos cierto que la programación sobre política suele tener grandes audiencias. Los asuntos políticos cuentan con especial relevancia cuando los personajes implicados son relevantes y también cuando el país se encuentra en procesos electorales, donde el número de horas de emisión en la parrilla aumenta de forma espectacular y los telespectadores cuentan con una predisposición especial para el consumo de dicho tipo de productos. Fuera de éstos, los programas parlamentarios normalmente de carácter semanal suelen emitirse en cadenas generalistas estatales y públicas, ya que su audiencia residual hace inviable la difusión por medio de canales privados. 


\section{Programas de medio ambiente}

Tratado el medio ambiente de una forma absolutamente general podremos realizar una pequeña distinción de productos referidos a la ciencia, a diferentes técnicas, a la información sobre la fauna y la flora, etc. Este tipo de programas cuenta con importancia programática en alguna de las cadenas y con audiencia escasa y fiel, lo que se traduce en horarios no especialmente viables para un consumo masivo.

\section{Programas culturales}

Se incluyen obras teatrales, material cinematográfico, exposiciones, conciertos, óperas, etc., en definitiva cualquier tipo de representación artística y cultural. Todas las cadenas cuentan con este tipo de material en su programación, siendo la proyección de material cinematográfico una de las principales apuestas y, junto a los deportes, lo que rompe límites en los índices de audiencias. Y en muchas de las cadenas la oferta cultural únicamente se circunscribe a dicho material, aunque existen otras cadenas que por sus características cuentan con una programación especialmente cultural. El caso de la segunda cadena de la televisión pública española es, sin duda, una buena excepción en lo referente a programación cultural pero con audiencias poco competitivas.

\section{Información meteorológica}

Algunos autores incluyen la información meteorológica como un tipo de programas de información diferente a los propios noticiarios. Se estima que dicha distinción es un tanto arbitraria y en parte no justificada. La realidad muestra que la información "del tiempo" suele estar incorporada en los servicios informativos de las cadenas, tanto es así que lo incluyen en el mismo programa, mientras que otros lo envuelven tras una pequeña pausa publicitaria, y siempre está unido programáticamente a los noticiarios, siendo realmente raro el poder encontrar un programa única y exclusivamente meteorológico, salvo por catástrofes naturales.

\section{GESTIÓN DOCUMENTAL DE PROGRAMAS DE ENTRETENIMIENTO}

El sujeto de análisis a estudiar será el documento televisivo audiovisual de programas no informativos. Dicha división entre programas de entretenimiento y programas informativos suele ser habitual en los diferentes departamentos de documentación de las televisiones ya que los requerimientos de los usuarios, atendiendo a este tipo de producto, es absolutamente diferente. Tanto es así, que la escasa literatura existente sobre el análisis de material audiovisual se centra en los programas informativos al ser más sencillo al contar con unas características visuales diferentes, derivado especialmente de la procedencia de las imágenes. Mientras que informativos puede contar con material de agencias nacionales y/o internacionales, corresponsalías, centros territoriales, etc. en los programas de entretenimiento la información es, en la mayor parte de los casos, material en estudio y propio. Lo dicho no significa que programas de entretenimiento no pueden contar con una parte informativa - ejemplo de ellos son los magazine, reality show o info show en general -, la diferencia es que dicha información estará tratada por los departamentos de documentación de los servicios informativos y no por los departamentos de programas. De todas maneras, y como apuesta personal, se estima que la centralización de todas las operaciones documentales en un mismo departamento es una buena solución tanto para optimización de recursos económicos y humanos como mejor fórmula de control documental en las organizaciones.

Las fases de análisis coinciden con cualquier otro producto visual: visionado, análisis formal y de contenido, almacenamiento y difusión. No se estima oportuno señalar dichos aspectos realizados con anterioridad por Fournial (1986, p. 249-258), por el Manual de documentació Audiovisual e ràdio i televisió (1999, p. 78)), Antonio Hernández Pérez (1992), López de Quintana (2000), Hidalgo Goyanes (1999) y Caldera Nuño (2002) que realizan una revisión de diferentes autores.

La entrada del material suele ser generado por la propia actividad empresarial, siendo en muchos casos material propio o productos comprados a terceros. La tónica habitual en las televisiones estatales y autonómicas españolas es la asociación con productoras para la creación de diferentes productos de entretenimiento, por lo que se cuenta con una doble coautoría del producto: la propia cadena y la productora. Este material, creado por la propia empresa va a ser conservado, independientemente de su valor potencial de reutilización, como activo patrimonial y empresarial. Conservar la producción propia parece cuestión no sólo inevitable sino absolutamente coherente.

Por lo tanto, no se llevará a cabo una selección sobre dichos productos, ya que al ser material de la compañía deberá conservarse, al menos, un premontaje o paralelo de antena. 
Cuestión diferente serán los criterios de selección del material adquiridos a terceros como pueden ser grandes cadenas de televisión o productoras audiovisuales. Habrá que determinar no sólo su potencial de reutilización sino la posibilidad de llevarla a cabo. Se debe analizar los aspectos legales y de derechos de reutilización de este tipo de material, aspectos que cada vez con mayor frecuencia están siendo realizados por los departamentos de documentación.

El tratamiento documental, realizado a través de las fases de análisis someramente indicadas y exhaustivamente referenciadas, suele traducirse en la implementación de una base de datos documental en la cual se indican aspectos formales y de contenido. Dichos aspectos, que sin duda están cambiando con el presente proceso de digitalización, no podrán ser olvidados aunque sean evidentes los cambios que produce la tecnología.

Los documentos susceptibles de ser tratados con esta metodología son los documentos generados a partir de la tipología documental señalada con anterioridad. Se va a realizar la descripción de la base de datos, mostrando así las necesidades de los usuarios así como su conservación y almacenamiento en la herramienta documental, que se traduce en el análisis formal y análisis de contenido, lo cual en parte no deja de ser una división un tanto artificial cuando de lo que realmente se trata es de ofrecer la posibilidad de mostrar puntos de acceso.

Las áreas en las que deben aglutinarse los documentos son las de control, descripción física, título, descripción, descriptores (temáticos, onomásticos, geográficos, cronológicos), producción, emisión, localización y responsabilidad.

\section{Área de control}

El área de control tiene la utilidad de controlar la producción de los analistas/documentalistas. Pensar que dicha información debiera omitirse no deja de ser una utopía ya que la totalidad de las empresas no sólo controlan la producción de los documentalistas sino que también es una forma de responsabilizar al personal de las acciones documentales, algunas de ellas delicadas, tales como la selección y el expurgo. Igualmente cuenta con otra serie de campos destinados para el control propio del documento como registro informático documental. Estos campos posibles pueden ser el número de registro del documento en el sistema informático, fecha de entrada en el sistema de información informatizado, código que identifica al documentalista y un histórico sobre el análisis documental en el que se indicará cualquier modificación que pudiera haber sufrido el documento, tales como especificaciones de nuevos descriptores o corrección en el control de autoridades.

Por lo tanto, los campos potenciales de dicha área son:

Número de registro.

Entrada en el sistema.

Documentalista.

Histórico de análisis.

\section{Área de descripción física}

Otra información a describir en el área de descripción física son aspectos puramente formales del documento, como la existencia de código de tiempo, características técnicas del audio y el vídeo, aspectos que identifiquen tanto al soporte como al formato, forma audiovisual en la que está presentado la información, sistema de grabación y la duración total del documento audiovisual analizado.

Los campos a confeccionar serían:

Código de tiempo.

Audio.

Vídeo.

Soporte.

Formato.

Forma.

Grabación.

Duración.

\section{Área de designación/título}

El área de designación o título es de más fácil confección que en programas informativos ya que los productos no siempre cuentan con un título, por lo que deberá ser aportado un título documental. Pero en el caso que nos preocupa el título es ofrecido por la empresa audiovisual, por lo que tan solo se debe transcribir aquella información aportada por la propia empresa. Título del programa, título de la serie (en caso de que dicho producto esté integrado en una serie con denominación común), subtítulos y el número del documento que lo identifique y lo ordene en la serie.

Los campos del área de título/designación son:

Título programa.

Título serie.

Subtítulo.

Número de serie. 


\section{Área de descripción}

Conforme al área de descripción, seguramente la más problemática a la hora de la implementación, deberá contar con un resumen documental descriptivo del contenido de la obra audiovisual. En caso de que se considere oportuno también se podrá realizar un minutado con un nivel de exhaustividad mínima. Se estima que no es necesario dicho descripción de imágenes (también llamado minutado, análisis cronológico y/o contenido) aunque se deje como posibilidad cuando el programa de entretenimiento cuente con información propia que no sea tratada por los departamentos de documentación de los servicios informativos. Describir los planos de un programa que únicamente puede variar los personajes invitados o protagonistas no parece ser oportuno, salvo la indicación de estos nuevos protagonistas junto con la ubicación del soporte que contiene el nuevo documento.

Los campos para dicho área son:

Resumen.

Análisis cronológico / minutado.

\section{Área de descriptores}

En lo tratante a los descriptores temáticos, onomásticos y geográficos señalar la necesidad de distinguir entre contenidos visionados y referenciados por el documento. La práctica totalidad de las bases de datos de las televisiones autonómicas y estatales españolas cuentan con esta opción (con excepciones) ya que la asincronía potencial entre imágenes y sonido hace necesario dicha distinción. Por lo tanto, habrá que identificar temas visionados y temas referenciados; personas físicas, jurídicas y entidades visionadas y referencias, y lugares visionados y referenciados. Respecto a descriptores onomásticos se identificarán aquellos protagonistas del propio producto como aquellos que puedan ser visionados o referenciados en partes del documento.

Los campos en los que se indican los descriptores son:

\section{Área de Descriptores Temáticos}

Tema

Plano tema

Denotación temática

\section{Área de Descriptores Onomásticos}

Persona

Plano persona

Denotación persona

Entidad

Plano entidad

\section{Denotación entidad}

Autor

Intérprete

Colaboradores

\section{Área de Descriptores Geográficos}

Plano lugar

Plano localización

Implicación geográfica

\section{Área de producción}

Importante para la descripción de estos documentos son los datos relativos a la producción de la información, producción en la que habrá que señalar aspectos como quién cuenta con la propiedad del documento (propia, ajena o compartida), señalando información sobre la productora en caso de que no sea propia. Al igual que el productor o productora es necesario conocer información relativa de la empresa distribuidora. Dichos datos son relevantes y siempre unidos a la información relativa a los derechos de reproducción, emisión y comercialización. Los departamentos de documentación deben controlar dichos aspectos ya que la emisión de estos productos sin contar con la pertinente autorización puede acarrear graves y cuantiosos problemas legales, junto con pingues pérdidas para la compañía.

Los campos del área de producción son:

Propiedad.

Productora.

Fecha producción.

Distribución.

Género.

Derechos.

\section{Área de emisión}

Otro elemento descriptivo y de control se encuentra el área de emisión, en que debe señalarse el ámbito de difusión en caso de que la empresa cuenta con diferentes formatos y ámbitos geográficos de emisión de la 
información, fecha de la emisión como de las sucesivas reemisiones, periodo inicial y final de material emitido en formato seriado, la periodicidad, así como datos sobre la versión de la emisión, especialmente importante cuando el original es diferente al emitido. También se deberá señalar aspectos tales como el público destinatario (infantil, juvenil y/o familiar) al igual que información sobre el control de emisión (cadena, siempre y cuando la empresa cuente con más de una).

Los potenciales campos a confeccionar en el área de emisión de los productos audiovisuales de entretenimiento son:

Ámbito de difusión.

Fecha primera emisión.

Fecha reemisión.

Emisión.

Período emisión.

Periodicidad emisión.

Versión emisión.

Versión original.

Público destinatario.

\section{Área de localización}

Se deberá mostrar aspectos para la localización del soporte documental en la videoteca, información que indicará el tejuelo que describe la ubicación física del material, así como número de registros del soporte y ubicación de potenciales copias de seguridad.

Los campos que identifican el material en el depósito, y el corte en el soporte, podrían ser los siguientes dependiendo de la empresa:

Signatura definitiva.

Signatura copias de seguridad.

Data cronológica.

Número de registro del soporte.

\section{Área de responsabilidad}

El penúltimo área a señalar es el de responsabilidad, en el cual se debe señalar los aspectos relativos a los miembros que han creado el producto audiovisual, en este caso coinciden con los créditos del producto televisivo. Debe arbitrarse cuales son los elementos mínimos que deben indicarse en la descripción documental. Existen elementos que parecen, a todas luces, imprescindibles al ser autores intelectuales del producto como son la figura del director, realizador y productor, al igual que aquellos responsables de la presentación en cámara del programa informativo.

La información se estructura en los siguientes campos:

Director.

Realización.

Cuadro técnico.

\section{Área de miscelánea}

Para finalizar con la estructura de campos de la base de datos de gestión de documentos audiovisuales para programas de entretenimiento, se deja la posibilidad de señalar una serie de aspectos que no tienen cabida en el resto de campos. Para ello se utiliza esta área, también llamado de notas, pudiendo incorporar información sin cabida en el resto de campo y volver a indicar aquellos aspectos que se consideren especialmente relevantes, como la presencia de derechos de reutilización, cuestiones de conservación, etc. Igualmente se reserva un campo para especificar el potencial valor documental desde el punto de vista de la reutilización para este material. Indistintamente se cuenta con un campo para asociar, al registro documental audiovisual, otros materiales que pueden tener una valía para determinar el valor y para mejor interpretación de la información contenida, tales como los partes de grabación, escaletas, guiones, etc.

En el marco del área miscelánea se ofrecen los siguientes campos:

Valor documental.

\section{Observaciones}

Otros materiales a archivar.

Una vez analizadas las etapas de selección/adquisición y de análisis, tanto formal como de contenido de los documentos audiovisuales, analizaremos brevemente el apartado de la difusión de dichos productos.

Los usuarios potenciales de dicho material van a ser, muy especialmente, los periodistas de la propia cadena que necesiten recursos audiovisuales para la realización de nuevos productos, ya sea reutilizando el programa de entretenimiento completo o para la reutilización de fragmentos de los mismos. Pero no solo van a ser los periodistas de la propia cadena quién pueda solicitar y reutilizar dicho material. La venta de imágenes de archivo es un negocio floreciente para todas aquellas cadenas que gestionan de manera eficiente sus fondos, la 
explosión de televisiones locales está planteando un nuevo panorama audiovisual donde es necesario la compra de imágenes por parte de éstas. Existen otra serie de compradores tradicionales como son las productoras de televisión, agencias de publicidad, telespectadores en general e incluso otras televisiones nacionales o extranjeras.

El uso que puede darse a esta información trasciende lo estrictamente documental, aunque la experiencia nos ofrece la posibilidad de señalar que dicha documentación suele ser utilizada por el personal de la propia empresa para crear nuevos productos. Su utilidad varia, siendo útil para verificar, contextualizar o ayudar a la caracterización (en caso de programas humorísticos). Aunque existe un cierto resurgir en la utilización de archivo son escasos aún los programas que han observado la potencialidad de dichos recursos.

Los usuarios pueden solicitar y solicitan tanto los productos completos para su reemisión, así como recursos de personas, lugares y temas que conforman las partes de los documentos audiovisuales que integran la base de datos audiovisual, recursos que pueden ser utilizados en su totalidad o únicamente aquellos fragmentos que se consideren válidos para la creación del nuevo producto televisivo.

\section{CONCLUSIONES}

La gestión de la información en la televisión es un ejercicio lento y arduo, lo que se traduce en requerimientos importantes tanto en recursos humanos como recursos económicos, y esta es una de las principales dificultades para la correcta gestión de la información audiovisual en televisión.

La dificultad empresarial se complica con otra serie de elementos que imposibilitan, a priori, la gestión de la información audiovisual televisiva como es la falta de profesionales especializados en la gestión de este tipo de material. Aunque su entrenamiento es relativamente sencillo son escasas las universidad que ofrecen este tipo de formación a sus egresados, por lo que es necesario llevar a cabo cursos de aprendizaje y posteriormente de perfeccionamiento por partes de las empresas televisivas.

Además, si han analizado con espíritu crítico el tipo de base de datos mostrada observarán que en poco se parecen a los gestores de bases de datos convencionales y los datos a designar son indudablemente superior en número y complejidad al existente para el análisis de otros materiales no audiovisuales.
Pero sobre todas estas dificultades está el usuario. Principio y fin de toda gestión documental. Esta usuario cuenta con la capacidad de mutar de requerimientos con gran rapidez, como rápidamente evolucionan las modas informativas de entender y de hacer televisión. Esto hace necesario el contacto y estudio constante de los periodistas para así detectar dichas mutaciones modificando el análisis y estudio de la información audiovisuales.

Todo lo expuesto en estas conclusiones no deben interpretarse como problemas sino como retos que los gestores de información audiovisual televisiva deben afrontar y superar ya que estos Servicios son claves en la producción de información televisiva por el abaratamiento de los costes y por el valor de reproducción y patrimonial con la que cuenta la información audiovisual. La televisión habría existido sin los Departamentos de Documentación, sin embargo su evolución y sus productos hubieran contado con mucha menor calidad de las que pueden verse en la actualidad.

La correcta gestión de la información es un reto que aún hoy se sigue implementando y desarrollando por las empresas, siendo un área olvidada en el Information Science actual. Deben desarrollarse estudios, análisis y proyectos de investigación en esta materia y animamos a investigadores en las áreas de la Documentación, la Computación, la Lingüística, la Iconografía, la Semiótica, ..., a que desarrollen su labor en la mejora y perfeccionamiento de las técnicas y tácticas de la información audiovisual.

Artigo submetido em 24/02/2006 e aceito em 10/07/2006.

\section{REFERENCIAS}

ABADAL FALGUERAS, E. Diseño y creación de una base de datos en un medio de comunicación. In: MANUAL de documentación periodística. Madrid: Síntesis, 1995. p. 195-211.

AUDIOVISUAL archives: a practical reader. Paris: UNESCO, 1997.

AROZIN LOPEZ, Virtudes; LOPEZ BRUÑET, Trinidad. Problemas que presenta la descripción de imágenes en la elaboración de bases de datos multimedia. In: JORNADAS ESPAÑOLAS DE DOCUMENTACIÓN CIENTÍFICA, 4., 1994, Gijón. Anales... Gijón: Universidad de Oviedo. Servicio de Publicaciones, 1994. p. 411-416.

BARROSO GARCÍA, Jaime. Realización de los géneros televisivos. Madrid: Síntesis, 1996.

BLUM, Richard A.; LINDEHEIM, Richard D. Programación de las cadenas de televisión en horarios de máxima audiencia. Madrid: Instituto Oficial de Radio Televisión España, 1997. 


\section{Jorge Caldera-Serrano}

CALDERA SERRANO, Jorge; NUÑO MORAL, María Victoria. Etapas del tratamiento documental de imagen en movimiento para televisión. Revista General de Información y Documentación, v. 12, n. 2, p. 375-392, 2002.

CEBRIAN HERREROS, Mariano. Bibliografía de la información audiovisual. Madrid: Instituto Oficial de Radio y Televisión, 1986.

$\overline{3}, 1992$. Géneros informativos audiovisuales. Madrid: Ciencia

Información audiovisual: concepto, técnica, expresión y aplicaciones. Madrid: Síntesis, 1995.

Información televisiva: mediaciones, contenidos, expresión y programación. Madrid: Síntesis, 1998.

CONESA, Alicia. La documentación en los medios de comunicación audiovisual. In: MANUAL de Documentación Periodística. Madrid: Síntesis, 1995, p. 147-159.

CONTRERAS, José Miguel; PALACIO, Manuel. La programación en televisión. Madrid: Síntesis, 2001.

FERNANDEZ MARTIN, Tomás. Lenguaje controlado y lenguaje libre en el análisis del audiovisual. In: LA dOCUMENTACIÓ als mitjand d'informació: l'experiència multimèdia. València: Generalitat Valencia, 1994, p. 249-251.

FOURNIAL, Catherine. Análisis documental de imágenes en movimiento. In: PANORAMA de los archivos audiovisuales. Madrid: Servicios de Publicaciones de RTVE, 1986. p. 249-258.

HARRISON, Harriet W. Who, what, when and why?: access to films though the cataloge. IFLA Journal, v. 18, n. 3, p. 238-242, 1992.

HERNANDEZ PEREZ, Antonio. Documentación audiovisual: metodología para el análisis documental de la información periodística audiovisual. Madrid: Universidad Complutense, 1992.
HIDAlgO GOYANES, Paloma. Análisis documental de audiovisuales. In: INTRODUCCIÓN a la documentación informativa y periodística. Sevilla: MAD, 1999. p. 333-350.

LOPEZ DE QUINTANA, Eugenio. Integración del centro de documentación en los procesos de producción de televisión. In: LA DOCUMENTACIÓ als mitjans d'informació: l'experiència multimédia. València: Generalitat Valenciana, 1994. p. 221-236.

Eugenio. Documentación en televisión. In: MANUAL de documentación informativa. Madrid: Cátedra, 2000. p. 83-181.

MANUAL de documentació audiovisual en ràdio i televisió. València: Universitat, 1999.

MANUAL de documentación informativa. Madrid: Cátedra, 2000.

MANUAL de documentación periodística. Madrid: Síntesis, 1995.

MUÑOZ MUÑOZ, Ana María; JIMENEZ VELA, R. Revisión del concepto de archivo audiovisual: una bibliografía anotada. In: JORNADAS BIBLIOTECARIAS DE ANDALUCÍA, 9., 200-?, Andalucía. Anales... Andalucía: [s.n.], 200-?. p. 414-427.

SANABRIA, Francisco. Información audiovisual: teoría y técnica de la información radiofónica y televisiva. Barcelona: Bosch Comunicación, 1994.

SCHMULAND, Arlene. The archival image in fiction: an analysis and annotated bibliography. The American Archivist, v. 62, n. 1, p. 2473, Spring 1999

SUSSMAN, Scott. Así se crean programas de televisión. Barcelona: Rosal Jai, 1995.

YEE, M. The concept of work for moving imagen materials. Cataloguing E Classification Quaterly, v. 18, n. 2, p. 33-40, 1993. 